\title{
Ebeveyn Öz Yeterlik Ölçeği Geçerlik ve Güvenirlik Çalışmasının Güncellenmesi ${ }^{1}$
}

\section{The Updating for Study of Parental Self Efficacy Scale Validity and Reliabilitiy}

\author{
Atilla Cavkaytar* \\ Anadolu Üniversitesi, Türkiye \\ acavkayt@anadolu.edu.tr
}

\author{
Veysel Aksoy** \\ Pamukkale Üniversitesi, Türkiye \\ vaksoy@pau.edu.tr
}

\author{
Avşar Ardıç*** \\ Ege Üniversitesi, Türkiye \\ avsar.ardic@ege.edu.tr
}

\begin{abstract}
Özet
Bu çalışmanın amacı daha önce Guimond, Moore, Aier, Maxon, ve Diken (2005) tarafından geliştirilen Yetersizliği Olan Çocukların Ebeveynleri İçin Öz Yeterlik Ölçeğinin (Parental Self-Efficacy Instrument for Children with Disabilities-PSICD) Türkçe uyarlamasını güncellemek ve ölçeğin psikometrik özelliklerini (geçerlik ve güvenirlik) değerlendirmektir. Çalışmada, 151 anne (\%68.9), 63 baba (\%29.7) ve 3 diğer bakım veren (\%1.4) olmak üzere toplam 219 ağır ve orta derecede zihinsel yetersizliği olan çocuğa sahip ebeveynden elde edilen veriler kullanılmışıı.Yapılan geçerlik ve güvenirlik çalışmaları sonucunda, ölçeğin ölçtüğü özelliği tek boyutlu olarak ölçtüğü görülmüştür. Ölçeğin psikometrik özelliklerinin, ağır ve orta derecede zihinsel yetersizliği olan çocuğa sahip anne babaların ebeveynlik öz yeterlik düzeylerini belirlemede kullanılabilecek geçerli ve güvenilir bir araç olduğu bulunmuştur.
\end{abstract}

Anahtar Kelimeler: Ebeveyn öz yeterliği, Ağır ve orta derecede zihinsel yetersizlik, Özel Eğitim.

\begin{abstract}
Summary
The aim of this study is to update Turkish Version of Parental Self-Efficacy Instrument for Children with Disabilities - PSICD which was developed by Guimond, Moore, Aier, Maxon, and Diken (2005, and to identify its psychometric features (validity and reliability). In the study, the data was collected from 219 parents who have children with high and medium degree mental retardation. The participants were consisted of 151 mothers (\%68.9), 63 fathers (\%29.7), 3 other caretakers (\%1.4). As a result of validity and reliability studies, it was seen that the instrument measured the feature, which was asked to measure, as one-dimensional. It was found that the instrument was valid and reliable for identifying of parental self-efficacy levels of parents who have children with high and medium degree mental retardation.
\end{abstract}

Keywords: Parental self-efficacy; High and medium degree mental retardation; Special education.

\footnotetext{
${ }^{1}$ Bu çalışma TÜBİTAK (110K255) ve Anadolu Üniversitesi tarafindan desteklenen (1005E102) "e-ABDEP: Aile Bilgi ve Destek Eğitimi Programı: Zihinsel Yetersizliğe Sahip Çocuğu Olan Ebeveynlerin Eğitiminde Çevrimiçi Bilgilendirme ve Destek Hizmetleri Etkinliği” adlı proje kapsamında gerçekleştirilmiştir.

*Prof.Dr. Atilla Cavkaytar, Anadolu Üniversitesi, acavkayt@ gmail.com

**Öğr.Gör.Dr. Veysel Aksoy, Pamukkale Üniversitesi, vaksoy@ pau.edu.tr

***Yrd.Doç.Dr. Avşar Ardıç, Ege Üniversitesi, avsar.ardic@ege.edu.tr
} 


\section{Giriş}

Öz yeterlik, bireylerin muhtemel durumlarla başa çıkabilmek için gerekli olan eylemleri ne kadar iyi yapabildiklerine dair yargıları olarak tanımlanmıştır (Bandura,1982). Diğer bir deyişle bireyin, belli bir performansı göstermek için gerekli etkinlikleri organize edip, başarılı şekilde yapma yeteneğine dair yargısıdır. Bandura'ya $(1994,1989)$ göre, öz yeterlik algısı, insanların kendilerine ilişkin düşünce ve duygularını etkileyebileceği gibi, belirli bir duruma yönelik güdülenme düzeylerini ve davranışlarını da etkileyebilir. Öz yeterlik algısı, yeterliliğimize yönelik bir inançtır. Amaçlarımıza ulaşmak için belirli davranışları organize etmek ve onu gerçekleştirmek için gereklidir (Yılmaz, Köseoğlu, Gerçek ve Soran 2004). Bandura'nın, öz yeterlik algısının bireyin; etkinliklerinin seçimini, güçlükler karşısındaki sebatını ya da ısrarc tutumunu, çabalarının düzeyini ve performansını etkilediği konusundaki görüşü birçok araştırmaya konu olmaktadır. Öz yeterlik inancı yüksek olan bireylerin, bir işi başarmak için büyük çaba gösterdikleri, olumsuzluklarla karşılaştıklarında kolayca geri çekilmedikleri, ısrarlı ve sabırlı oldukları belirtilmektedir (Aşkar ve Umay, 2001).

Bandura'nın öz yeterlik konusunda belirlediği çerçeveyle uyumlu olarak annelik ya da ebeveynlik öz yeterliği birçok çalışmada farklı şekillerde tanımlanmıştır. Ebeveynlik öz yeterliğinin, ebeveynlerin; ebeveyn rollerini bilgili ve yeterli olarak yerine getirmelerine dair beklentilerinin derecesi (Teti ve Gelfand,1991), çocuklarının davranış ve gelişimleri üzerinde olumlu etki bırakabilmeye dair algılar (Coleman, 1998), kendilerini ebeveynlik rollerinde yeterli görme dereceleri (Hassall, Rose ve McDonald, 2005) gibi farklı tanımları yapılmıştır. de Montigny ve Lacharite (2005) ebeveynlik öz yeterliği kavramının kullanım biçimlerine ve niteliklerine dair yaptıkları meta analiz ile kavramın bileşenlerini belirlemiş ve ebeveynlik öz yeterliğini tanımlamışlardır. Buna göre, algılanan ebeveynlik öz yeterliği, "ebeveynin çocuğunun bakım ve yetiştirilmesiyle ilgili bir takım görevler hakkında sahip olduğu kendi kapasitesine dair yargıları ve inançları" olarak tanımlanmışıır.

Haidt ve Robin (1999), öz yeterlik inançlarının birçok bağlamdaki başarı ve performans için en iyi öngörüyü sağladıklarını belirtmişlerdir. Bandura (1997), yeterlik inançlarının ebeveynlik uygulamalarının önemli temellerinden biri olduğunu belirtmektedir. Annelik öz yeterliği inancının birçok psiko-sosyal değişken ve annelik yeterliği arasında aracı olarak işlediği, öz yeterlik inancının depresyon etkileri, sosyal destekler ve yeni doğanın mizacı ile annelik davranışları arasında aracı etkisi olduğu bildirilmiştir (Teti ve Gelfand,1991). Yine çocukların problem davranışları ile annelerin ebeveynlik öz yeterlik inancı arasında ilişki olduğu belirtilmektedir (Hassall, Rose ve McDonald, 2005; Maniadaki, Sonuga-Barke, Kakouros ve Karaba, 2005; Sanders ve Woolley, 2005).

Erken çocukluk dönemi gelişimde kritik öneme sahiptir ve çocuğun bu dönemdeki gelişimi ileri yıllardaki gelişimini de doğrudan etkilemektedir. Luebering (1995), ilk kez anne olan yeni doğan anneleriyle yaptığı çalışmada ebeveynlik öz yeterlik algısıyla bebek bakımına dair inançlar arasında olumlu bir ilişki olduğunu bildirmiştir. Annelik rolleri ile ebeveyn öz yeterlik algısı arasında olumlu bir ilişki olduğunu ve anne olmaktan mutluluk duyan annelerin kendilerini daha fazla yeterli hissettiklerini, algılanan ebeveyn öz yeterliği ile uygun ebeveynlik beceri ve davranışlarının birbirleriyle bağıntılı olduğunu belirtmiştir. Öz yeterlik inançlarına dair algının anne-baba davranışları için öngörü sağladığı ve yüksek öz yeterlik algısına sahip annelerin daha uygun ebeveyn uygulamaları gerçekleştirdikleri bildirilmektedir (Coleman ve Karraker, 2000; Luebering 1995; Teti ve Gelfand,1991).

Yüksek ebeveynlik öz yeterlik algısına sahip annelerin çocuklarına uygun çevresel ortamlar oluşturdukları ve daha az cezalandırıcı oldukları, bebeklerinin verdikleri işaretlere daha duyarlı oldukları, bebekleriyle etkileşimde etkin ve sorumluluk alan anneler oldukları belirtilmektedir (Coleman ve Karraker, 2000). Bu annelerin bebekleriyle iletişimde duyarlı ve içten oldukları ve sorumluluk duygusuyla hareket ettikleri belirtilmiştir (Teti ve Gelfand,1991). Ebeveyn öz yeterlik algısı, özellikle erken çocukluk döneminde gelişimi risk altında olan ya da gelişimsel gerilik gösteren bebeklerin ebeveynlerinin çocuğun gelişime sağlayacakları katkı önemli olduğundan bu özelliği sağlıklı bir biçimde ölçen araçların varlığı profesyoneller açısından önem taşımaktadır.

Bu çalışmanın amacı daha önce Guimond, Moore, Aier, Maxon, ve Diken (2005) tarafından geliştirilen Yetersizliği Olan Çocukların Ebeveynleri İçin Öz Yeterlik Ölçeğinin (Parental Self-Efficacy Instrument for Children with Disabilities-PSICD) Türkçe uyarlamasını güncellemektir. Türkiye'de ilk olarak Diken 
(2007) tarafından Türkçeye uyarlanmış ve dil becerilerinde gecikme gösteren çocuğa sahip Türk annelerinin öz yeterlik algılarını değerlendirmek amacıyla kullanılmıştır. Daha sonra aynı ölçek Beral (2010) tarafından otistik bozukluk tanısı almış çocukların ebeveynleri ile yapılan çalışmada kullanılmıştır. Diken (2007) nin çalışmasında ölçeğin yapı geçerliği yönünden incelenmesi yapılmamış Beralın çalışmasında da orijinal ölçekten 4 madde elenmiştir. Bu çalışmada ağır ve orta düzey zihinsel yetersizlik tanısı almış çocukların ebeveynlerinden toplanan veriler üzerinden ölçeğin Türkçeye uyarlanmasının yapılması amaçlanmaktadır.

\section{Çalışma Grubu}

\section{Yöntem}

Bu çalışmada Türkiye'nin altı ilinde (İstanbul, Ankara, İzmir, Denizli, Eskişehir ve Muğla) MEB Eğitim Uygulama Okulları'nda eğitim alan orta ve ağır düzeyde zihinsel yetersizliği olan çocukların 151 anne (\%68.9), 63 baba (\%29.7) ve 3 diğer bakım veren (\%1.4) olmak üzere toplam 219 ebeveyninden elde edilen veriler kullanılmışıı. Katılımcıların yaşları 26 ile 61 arasında değişmekte olup ortalaması 41.18 ve standart sapması 6.5 olarak bulunmuştur. Aracın uygulamasında araştırmacılar görev almış ve okuma yazma bilmeyen ebeveynlere araç doğrudan okunarak uygulanmıştır. Bu uygulama sonunda altı ilden toplam 248 katılımcıya ulaşıımıştır. Katııımcılar tarafından doldurulan formlar incelendiğinde istatistiksel olarak kullanılabilir olan 219 form ile istatistiksel analizler gerçekleştirilmiştir. Ölçeğin uygulandığı iller şunlardır; Ankara $(n=59)$, Denizli $(n=30)$, Eskişehir $(n=34)$, İstanbul $(n=53)$, İzmir $(n=17)$, Muğla $(n=26)$.

\section{İşlemler}

Çalışmada ilk olarak ölçeğin orijinal formunda ve Türkçe formunda yer alan maddeler alanda uzman akademisyenler tarafından dilsel değerlendirmeden geçirilmişlerdir. Orijinal ölçekte yer alan tersten puanlanan maddelerin Türkçede daha anlaşılır olması amacıyla bu maddeler olumlu ifade şeklinde yeniden formüle edilmişlerdir. Daha sonra bu araştırmada altı ilden 219 ebeveynden veriler elde edilmiştir. Eğitim Uygulama Okulu ve İş Okullarına devam eden öğrencilerin ebeveynlerinden veriler toplanmıştır.

\section{Verilerin analizi}

Verilerin analizinde SPSS paket programı kullanılarak yapı geçerliği boyutunda, açımlayıcı (exploratory) faktör analizi yapılmıştır. Cronbach Alpha iç tutarlık katsayıları incelenmiştir.

\section{Bulgular}

Açımlayıı faktör analizi yapılmadan önce ölçeği oluşturan maddelerin tamamı üzerinden madde toplam korelasyonuna ve Cronbach Alfa Katsayısına bakılmışır. Cronbach alfa katsayısı ölçeği oluşturan 17 madde üzerinden .95 olarak bulunmuştur. Ölçeği oluşturan 17 maddenin tamamı üzerinden madde toplam korelasyonu yapıldığında maddelerin madde toplam korelasyonları .52 ile .83 arasında değişmektedir.

\begin{tabular}{cccccc}
\hline Madde No & $\mathbf{r}$ & Madde No & $\mathbf{r}$ & Madde No & $\mathbf{r}$ \\
\hline 1 & .52 & 7 & .67 & 13 & .83 \\
\hline 2 & .58 & 8 & .73 & 14 & .79 \\
\hline 3 & .73 & 9 & .82 & 15 & .81 \\
\hline 4 & .59 & 10 & .77 & 16 & .74 \\
\hline 5 & .79 & 11 & .76 & 17 & .77 \\
\hline 6 & .72 & 12 & .78 & & \\
\hline
\end{tabular}

Tablo.1. Madde Toplam Korelasyon Değerleri 


\section{Geçerlik bulguları}

\section{Yapı geçerliği}

Yapı geçerliği boyutunda, ölçeğin faktör yapısını belirleyebilmek için açımlayıcı (exploratory) faktör analizi yapılmışır $(\mathrm{N}=219)$. Faktör analizinde,

1. KMO-Bartlett testinin istenilen düzeyde anlamlı çıkması,

2. Scree Plot grafiğinin incelenmesi,

3. Her bir maddenin faktör yük değerinin .32 den büyük olması,

4. Varyansın kabul edilebilir düzeyde olması, ölçüt olarak alınmıştır.

Faktör analizi yapılmadan önce maddeler arasında kısmi korelasyonların ve korelasyon matrisinin faktör analizi için uygun olup olmadığı Kaiser-Meyer-Olkin (KMO) katsayısı ve Bartlett Sphericity testi ile incelenmiştir.

Yapılan analizlerde, 17 maddenin faktör analizi için KMO değerinin 0.95 olduğu görülmüştür. Alanyazın incelendiğinde, verilere faktör analizi uygulanabilmesi için minimum KMO değerinin .60'ın üzerinde olması ve Bartlett testinin anlamlı çıkması önerilmektedir (Büyüköztürk, 2007; Pallant, 2001). Analiz sonucuna bakıldığında, KMO değerinin istenilen minimum değerin oldukça üzerinde olduğu görülmektedir. Benzer şekilde 17 maddenin Bartlett testi sonucu [ $x 2=3070.93 \mathrm{df}=136, p<.001]$ olarak bulunmuştur. Ölçeğin faktör yapısını belirleyebilmek amacıyla scree plot grafiği incelendiğinde, ölçeğin tek boyutlu bir yapı oluşturduğu görülmektedir.

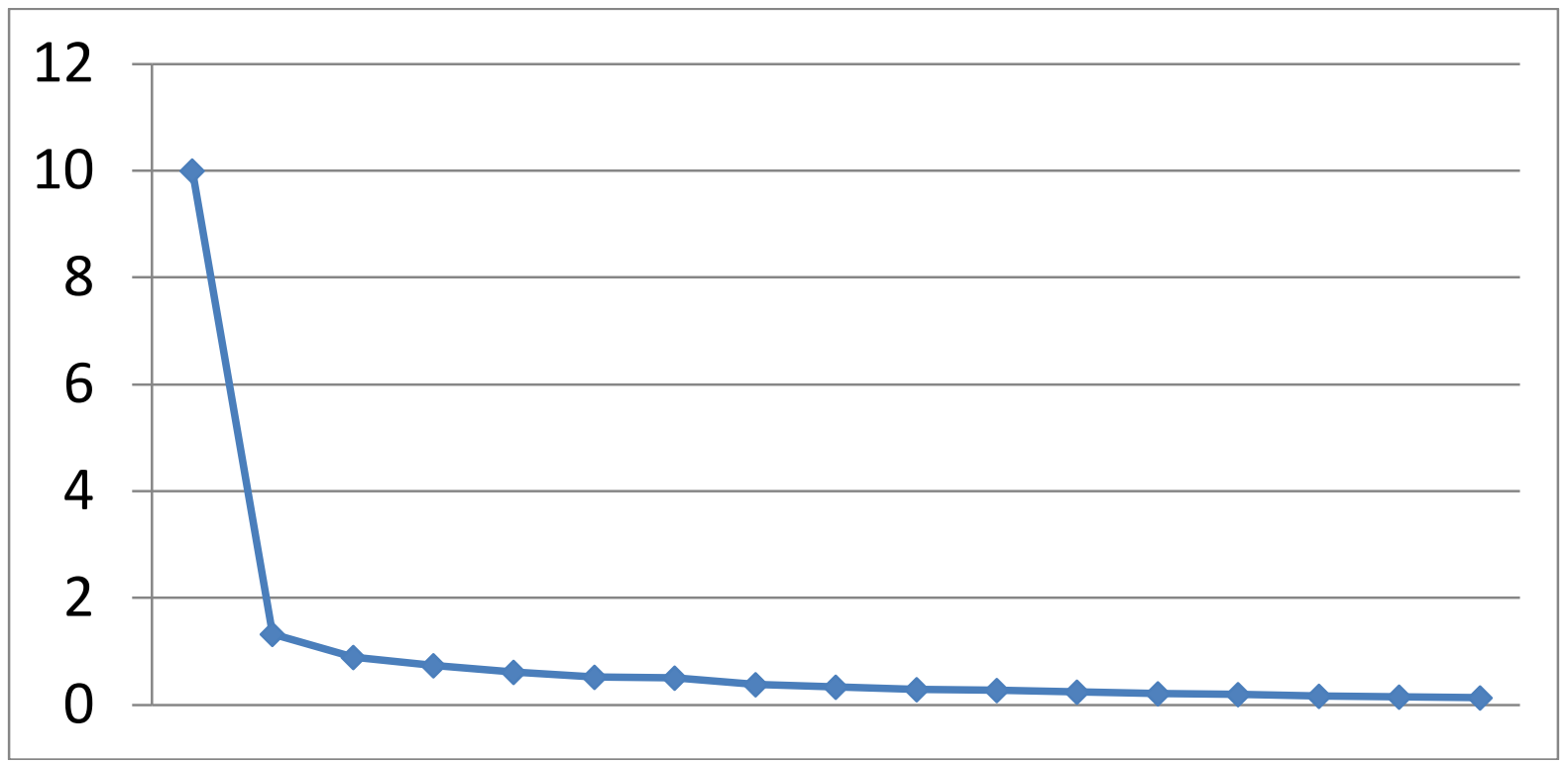

Daha sonraki adımda; ölçeğin yapı geçerliğini değerlendirmek üzere açımlayıcı (exploratory) faktör analizi yapılmıştır. Ölçeğin yapı geçerliğini belirlemek için Kaiser normalleştirmesine göre özdeğeri (eigenvalue) 1.00 'in üzerinde olan faktörler ölçüt alınmıştır. Analizler sonucunda toplam varyansın \%66.681'ini açıklayan 2 faktör elde edilmiştir. Temel bileşenler analizinden sonra varimax rotasyonu yöntemi kullanılarak yapılan döndürme işleminde temel bileşenler analiziyle elde edilen faktör yapısında önemli kabul edilebilecek bir değişme olmadığı görülmüştür. Bir ölçeğin tek boyutluluğunun belirlenmesinde, Birinci faktör yüküne ait özdeğerin ikinci faktör yüküne ait özdeğerden çok farklı olmasının ve ikinci faktör yüküne ait özdeğerin diğerlerinden çok farklı olmamasının bir ölçü olabileceğini belirtmektedir. Benzer şekilde, sosyal bilimlerde ölçeğin tek boyutlu olabilmesi için iki temel koşul ileri sürülmektedir. Bu temel koşullardan ilki, birinci faktörün açıkladığı varyans oranının toplam varyansın en az \% 30'u olması, ikincisi ise birinci faktörün özdeğerinin ikinci faktörün özdeğerinden 3 ila 3.5 kat daha büyük olmasıdır (Duru ve Balkıs, 2007). Scree Plot grafiği sonuçlarının yanında, faktör analizi sonuçlarında toplam varyansın \% 58.90'nını oluşturan 10.01 özdeğerli temel faktör olarak varsayılan birinci faktör ile yine toplam varyansın $\% 7.76$ 'sını oluşturan 
1.32 özdeğerli ikinci faktör arasında istenilen ölçüde fark olması ve birinci faktörün toplam varyansın \%58.90'nını tek başına açıklayabilmesi ölçeği tek boyutlu olarak varsayabileceğimizi göstermektedir.

\begin{tabular}{cccccc}
\hline Madde No & $\begin{array}{c}\text { Faktör Yük } \\
\text { Değeri }\end{array}$ & Madde No & $\begin{array}{c}\text { Faktör Yük } \\
\text { Değeri }\end{array}$ & Madde No & $\begin{array}{c}\text { Faktör Yük } \\
\text { Değeri }\end{array}$ \\
\hline 1 & .55 & 7 & .69 & 13 & .86 \\
\hline 2 & .61 & 8 & .77 & 14 & .83 \\
\hline 3 & .76 & 9 & .85 & 15 & .85 \\
\hline 4 & .62 & 10 & .81 & 16 & .77 \\
\hline 5 & .82 & 11 & .80 & 17 & .82 \\
\hline 6 & .74 & 12 & .80 & - & - \\
\hline
\end{tabular}

Tablo. 2 Ölçeğin tek faktörlü olarak yapılan faktör analizi sonuçlarına göre maddelerin birinci faktördeki faktör yük değerleri

\section{Güvenirlik bulguları}

Ölçeğin güvenirliğini belirlemek üzere, ölçeğin test-tekrar test güvenirliğine ve Cronbach Alfa iç tutarlık katsayılarına bakılmışır. Ölçeğin 30 ebeveynle 6 ay sonra yapılan test-tekrar test uygulaması sonucu Pearson korelasyon katsayısı, $r=0.79, p<0.001$ bulunmuştur. Ayrıca ölçekte yer alan maddelerin ölçmenin bütünüyle ne kadar tutarlı olduğunun bir diğer deyişle iç tutarlığının (benzeşikliğinin) bir ölçüsü olarak tüm ölçek için Cronbach Alfa katsayısı hesaplanmışıı. 219 katılımcıdan elde edilen veriler üzerinden ölçeğin Cronbach Alfa iç tutarlık katsayısı hesaplanmış ve bu değer $a=0.95$ olarak bulunmuştur.

\section{Tartışma}

Özellikle erken çocukluk döneminde gelişimi risk altında olan ya da gelişimsel gerilik gösteren bebeklerin ebeveynlerinin çocuklarının gelişimine sağlayacakları katkı normal gelişim gösteren çocuklarla kıyaslandığında daha da önemli olmaktadır. Normal gelişim gösteren çocuklar sahip oldukları yeterliliklerle daha fazla öğrenme ve gelişim olanağına sahipken, gelişimsel geriliği olan çocuklar normal akranlarıyla kıyaslandıklarında dezavantajlı durumdadırlar. Gelişimsel geriliği olan çocukların gelişimlerinin çevre tarafından desteklenmesi önemlidir. Çocuğun yakın çevresindeki en önemli kişiler ebeveynler ya da bakım verenlerdir. Ebeveyn öz yeterliğinin çocuğun gelişimine sağlanan katkıları göz önünde bulundurulduğunda alanda çalışan uzmanlar açısından ebeveyn öz yeterlik düzeyini ölçmenin önemi ortaya çıkmaktadır. Bununla birlikte ülkemizde özellikle erken çocukluk dönemi özel eğitim uygulamalarının göreli olarak yeni olması nedeniyle bu alanda yeterli sayıda ölçme aracının olmadığını söyleyebiliriz. Erken çocukluk döneminde uygulanan özel eğitim programları da sınırlı sayıdadır. Bu uygulamaların gerek uyarlanması gerekse de geliştirilmesi için uygulamaların etkililik ve verimliliğini test ederek uygulamaları bilimsel dayanaklı hale getirebilmek için benzer araçların uyarlanmasına ya da geliştirilmesine gereksinim bulunmaktadır. Bu nedenle gelecek araştırmalarda bu alandaki farklı özellikleri geçerli ve güvenilir olarak ölçecek araçlara gereksinim vardır. Ayrıca daha güçlü psikometrik bulgular elde edilebilinmesi için daha ileri istatistiksel analizler yoluyla yapılacak analizlere başvurulması önerilebilir. Örneğin ölçek uyarlama çalışmalarında doğrulayıcı faktör analizi bulgularının daha güçlü bilimsel kanıtlar ortaya çıkarabileceğini söyleyebiliriz. Bu araştırma kapsamında elde edilen veriler orta ve ağır düzeyde zihinsel yetersizliği olan ebeveynlerden elde edilen bulgularla sınırlıdır. Farklı engel gruplarından çocukları olan ebeveynlerde kullanılabilirliği sınırlılıklar içermektedir. Benzer çalışmaların farklı engel gruplarında yapılmasında yarar vardır. Ayrıca öz bildirim yoluyla elde edilen verilere ilişkin sınırlılıklar bu araç için de mevcuttur. 
Bu çalışmanın bulguları incelendiğinde, yapı geçerliği amacıyla yapılan faktör analizi çalışmasında özdeğeri 1 den büyük iki faktör oluşmuş ancak temel faktör dışındaki faktör istenilen istatistikî ölçütleri karşılayamamıştır. Bu nedenle daha büyük bir örneklemle çalışmanın yenilenmesi durumunda faktör yapısı yeniden şekillendirilebilinir. Ancak eldeki veriler ölçeğin bu haliyle tek boyutlu olarak kullanılabileceğini de göstermektedir. Maddelerin her birinin ölçme gücünü belirlemek amacıyla, korelasyonlara dayalı madde analizi yapılmışır. Toplam ölçek puanıyla yüksek ilişki gösteren maddeler, ölçme aracıyla ölçülmek istenen özelliğin ölçülmesine daha fazla katkıda bulunacağından ölçekte bu tür maddelere yer verilmesi gerektiği bildirilmektedir (Küçüker, 1997). Bu amaçla ölçekte bulunan 17 madde için hesaplanan madde-toplam puan korelasyon katsayıları kullanılmışır. Yapılan analiz sonucunda, maddelerin korelasyonlarının toplam ölçek puanıyla yüksek ilişki gösterdiği belirlenmiştir. Ölçekte yer alan tüm maddelerin $r$ değerlerinin .32 ' den büyük olması nedeniyle tüm maddelerin ayırt edicilik gücünün yüksek olduğu düşünülmüştür.

Güvenirlik bulguları incelendiğinde test-tekrar test ilişki düzeyinin ve Cronbach Alfa katsayısının istenilen düzeyde olduğu görülmektedir. Ölçeğin, güvenirlik ve geçerliğine ilişkin yapılan çalışmaların bulguları incelendiğinde, orijinal ölçektekinin aksine ölçeğin tek boyutlu olduğu ve Türkiye'deki ağır ve orta derecede zihinsel yetersizliği olan çocuğa sahip anne babaların ebeveynlik öz yeterlik düzeylerini belirlemede kullanılabilecek geçerli ve güvenilir bir araç olduğu düşünülmektedir.

\section{Kaynakça}

Aşkar, P., ve Umay, A. (2001). İlköğretim matematik bölümü öğrencilerinin bilgisayarla ilgili öz yeterlik algısı. Hacettepe Üniversitesi Eğitim Fakültesi Dergisi, 21, 1-8.

Bandura, A. (1982). Self-Efficacy mechanism in human agency. American Psychologist, 32(2), 122147.

Bandura, A. (1989). Social cognitive theory. Annals of Child Development Six Theories of Child Development, 6, 1-60.

Bandura, A. (1994). Self-efficacy. Encyclopedia of human behavior. 4. 71-81 Newyork: Academic Pres.

Bandura, A. (1997). Self-efficacy: The exercise of control. Freeman: New York.

Beral, Y. (2010). Otistik bozukluğu olan çocuğa sahip ebeveynlerin öz yeterlik algılarının belirlenmesi. Yayımlanmamış Yüksek Lisans Tezi. Eskişehir: Anadolu Üniveristesi Eğitim Bilimleri Enstitüsü.

Büyüköztürk, Ş. (2007). Sosyal bilimler için veri analizi el kitabı. Ankara: Pegema Yayıncılık.

Coleman, P. K. (1998). Maternal self-efficacy beliefs as predictors of parenting competence and toddlers' emotional, social, and cognitive development. Unpublished doctoral dissertation. The Eberly College of Arts and Sciences. West Virginia Univesity. Morgantown.

Coleman, P. K., \& Karraker, K. H. (2000). Parenting self-efficacy among mother of school-age children: conceptualization, measurement, and correlates. Family Relations 49, 13-24.

de Montigny, F., \& Lacharite, C. (2005). Nursing theory and concept development or analysis perceived parental efficacy: concept analysis. Journal of Advanced Nursing 49(4), 387-396.

Diken, I. H. (2007). Turkish mothers' self-efficacy beliefs and styles of interactions with their children with language delays. Early Child Development and Care, 179(4), 425-436.

Duru, E. \& Balkıs M. (2007). Sosyal provizyon ölçeğinin psikometrik özellikleri: geçerlik ve güvenirlik çalışması. Türk Psikolojik Danışma ve Rehberlik Dergisi, 27, 79-90.

Guimond, A., Moore, H., Aier, D., Maxon, E.\& Diken, I.H. (2005) Parental self-efficacy instrment for children with disabilities (PSICD). Unpublished scale.Arizona State University, Phoenix, AZ, USA.

Haidt, J., \& Robin, J. (1999). Control and efficacy as interdisciplinary bridges. Review of General Psychology 3, 317-337. 
Hassall, R., Rose J., \& McDonald, J. (2005). Parenting stress in mothers of children with an intellectual disability: the effects of parental cognitions in relation to child characteristics and family support. Journal of Intellectual Disability Research 49(6), 405-418.

Küçüker, S. (1997). Bilgi verici psikolojik danışmanlık programının zihinsel özürlü çocukların kardeşlerinin özürle ilgili bilgi düzeylerine ve özürlü kardeşlerine yönelik tutumlarına etkisi. Yayımlanmamış Doktora Tezi, Ankara: Ankara Üniversitesi Sosyal Bilimler Enstitüsü.

Luebering, A. (1995). The relationship between perceived parental self-efficacy and childrearing beliefs among first-time mothers of infant. Paper presented at the biennial meeting of the society for research in child development. Indianapolis, IN, March 30-April 2.

Maniadaki, K., Sonuga-Barke, E., Kakouros, E., \& Karaba, R. (2005). Maternal emotions and selfefficacy beliefs in relation to boys and girls with AD/HD. Child Psychiatry and Human Development 35(3), 245-263.

Pallant, J. (2001). SPSS Survival Manuel. A Step-By-Step Guide to Data Analysis Using SPSS for Windows. Philadelphia, PA: Open University Press.

Sanders, M. R., \& Woolley, M. L. (2005). The relationship between maternal self-efficacy and parenting practices: implication for parent training. Child: Care, Health \& Development, 31(1), 65-73.

Teti, D. M., \& Gelfand, D. M. (1991). Behavioral competence among mothers of infants in the first year: the meditational role of maternal self-efficacy. Child Development 62, 918-929.

Yılmaz, M., Köseoğlu, P., Gerçek, C., \& Soran, H. (2004). Öğretmen öz yeterlik inancı. Bilim ve Aklın Aydınlığında Eğitim Dergisi, 5.

\section{EXTENDED ABSTRACT}

The aim of this study was previously to update the Turkish adaptation of Parental Self-Efficacy Instrument for Children with Disabilities (PSICD) which developed by Guimond, Moore, Aier, Maxon, and Diken (2005). This instrument was firstly adapted by Diken to Turkish culture and used for assessing the perceptions of self-efficacy of Turkish mother whose children with language delayed. Later, the same instrument was used by Beral (2010) in a study of parents whose children with autism. The construct validity of this instrument was not examined in the Diken's study (2007). However, 4 items of the original scales was disqualified for the adapted version of this scale in the Beral's study (2010). In this study, the main purpose was that Parental Self-Efficacy Instrument for Children with Disabilities (PSICD) was adapted the Turkish culture with using the data which gathered parents of children with severe and moderate intellectual disabilities.

\section{Method}

Data which used in this study obtained from 219 parents who live in İstanbul, Ankara, İzmir, Denizli, Eskişehir and Muğla. 151 (\%68.9) of these parents are mothers, 63 (\%29.7) of them are fathers and 3 (\%1.4) of them are other caregivers. A age of participants ranged from 26 to 61 , mean of their age is 41.18 and standard deviation of their age is 6.5 .

\section{Procedure}

In this study, academics, who are expert in the field of language, passed the items of original format of scale and Turkish version of it in language review. Reverse scored items in the original format of scale in order to be more understandable in Turkish, they are reversed to a positive statement in Turkish version of the scale. After data was gathered from 219 parents who lives six cities. Children of these parents are students of Education Application and Business School.

In analysis of data, exploratory factor analysis was conducted for construct validity of this scale. In addition, Cronbach's Alpha Coefficients was calculated for internal consistency. 


\section{Results and Discussion}

When examining construct validity result, the PSICD has two main factor with eigenvalues greater than 1. However, one of these factors has not the desired statistical criteria. Therefore, the Turkish version of PSICD has only one factor. Factor structure of the Turkish version of PSICD may be change by gathering data from greater sample. Items of the Turkish version of PSICD have high itemtotal correlation coefficients. All items in the Turkish version of PSICD have $r$ values which greater than .32. Therefore, it can be said that item discrimination index of items is fine. Examined the findings of reliability analysis, test-retest correlation and Cronbach's alpha coefficient is seen that the desired level.

Examined the findings of reliability and validity of PSICD, unlike original format of scale, the Turkish version of it has one-dimensional scale and it can be said that the Turkish version of PSICD is reliable and valid instrument for using to determine the levels of parenting self-efficacy of parents having a child with severe and moderate intellectual disabilities in Turkey. 